\title{
Loss of genetic variability in a hatchery strain of Senegalese sole (Solea senegalensis) revealed by sequence data of the mitochondrial DNA control region and microsatellite markers
}

\author{
PABLO SÁNCHEZ ${ }^{1,2}$, JORDI VIÑAS ${ }^{3,4}$, JAIME R. ALVARADO BREMER ${ }^{3,5}$, \\ PEDRO PABLO AMBROSIO ${ }^{1,2}$ and ROSA FLOS ${ }^{1,2}$
}

${ }^{1}$ Departament d'Enginyeria Agroalimentària i Biotecnologia, Universitat Politècnica de Catalunya. Esteve Terradas, 8, 08860 Castelldefels, Barcelona, Spain. E-mail: pablo.sanchez@gmail.com

${ }^{2}$ Centre de Referència de Recerca i Desenvolupament en Aqüicultura de la Generalitat de Catalunya.

${ }^{3}$ Department of Marine Biology, Texas A\&M University at Galveston, Ocean and Coastal Studies Building, 1001 Texas Clipper Road, Galveston, TX 77553. USA.

${ }^{4}$ Present address: Laboratori d'Ictiologia Genètica, Departament de Biologia, Universitat de Girona, Campus Montilivi, E-17071, Girona, Spain.

${ }^{5}$ Department of Wildlife and Fisheries Sciences, Texas A\&M University, 210 Nagle Hall, TAMU 2258, College Station, TX 77843, USA.

SUMMARY: Comparisons of the levels of genetic variation within and between a hatchery $\mathrm{F}_{1}(\mathrm{FAR}, \mathrm{n}=116)$ of Senegalese sole, Solea senegalensis, and its wild donor population (ATL, $n=26$ ), both native to the SW Atlantic coast of the Iberian peninsula, as well as between the wild donor population and a wild western Mediterranean sample (MED, $n=18$ ), were carried out by characterizing 412 base pairs of the nucleotide sequence of the mitochondrial DNA control region I, and six polymorphic microsatellite loci. FAR showed a substantial loss of genetic variability (haplotypic diversity, $h=0.49 \pm 0.066$; nucleotide diversity, $\pi=0.006 \pm 0.004$; private allelic richness, $p A g=0.28)$ to its donor population ATL $(h=0.69 \pm 0.114$; $\pi=0.009 \pm 0.006 ; p A g=1.21)$. Pairwise $F_{S T}$ values of microsatellite data were highly significant $(P<0.0001)$ between FAR and ATL (0.053) and FAR and MED (0.055). The comparison of wild samples revealed higher values of genetic variability in MED than in ATL, but only with mtDNA CR-I sequence data $(h=0.948 \pm 0.033 ; \pi=0.030 \pm 0.016)$. However, pairwise $\Phi_{S T}$ and $F_{S T}$ values between ATL and MED were highly significant $(P<0.0001)$ with mtDNA CR-I $(0.228)$ and with microsatellite data (0.095), respectively. While loss of genetic variability in FAR could be associated with the sampling error when the broodstock was established, the results of parental and sibship inference suggest that most of these losses can be attributed to a high variance in reproductive success among members of the broodstock, particularly among females.

Keywords: Solea senegalensis, genetic variability, mitochondrial DNA Control Region, microsatellite loci, broodstock management, variance in reproductive success, flatfish.

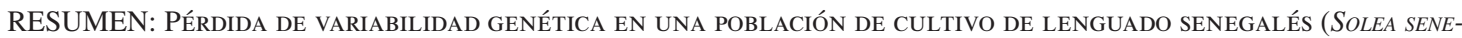
GALENSIS) REVELADA MEDIANTE DATOS DE SECUENCIA DE LA REGIÓN CONTROL DEL ADN MITOCONDRIAL Y DE MARCADORES Microsatélite. - Se compararon los niveles de variabilidad genética de la $\mathrm{F}_{1}$ de una población de cultivo (FAR, n=116) de lenguado senegalés, Solea senegalensis, y de una muestra de su población de origen (ATL, n=26), ambas provenientes del SO de la península ibérica (Atlántico), así como entre esta última y una muestra de individuos salvajes del Mediterráneo occidental (MED, $n=18$ ), mediante la caracterización de una secuencia de 412 pares de bases de la Región Control-I del ADN mitocondrial, y de seis loci microsatélite. FAR experimentó una reducción sustancial de variabilidad genética (diversidad haplotípica, $h=0.49 \pm 0.066$; diversidad nucleotídica, $\pi=0.006 \pm 0.004$; riqueza de alelos privados, $p A g=0.28$ ) respecto a su población original ATL ( $h=0.69 \pm 0.114 ; \pi=0.009 \pm 0.006 ; p A g=1.21$ ). Los valores de $F_{S T}$ entre poblaciones, calculados a partir del análisis de los microsatélites, fueron altamente significativos $(p<0.0001)$ para FAR y ATL $(0.053)$, y para FAR y MED (0.055). La comparación de las dos muestras salvajes mostró mayores niveles de variabilidad genética en MED que en ATL, pero únicamente en marcadores mitocondriales $(h=0.948 \pm 0.033 ; \pi=0.030 \pm 0.016)$. Sin embargo, los valores de $\Phi_{S T}$ 
y $F_{S T}$ presentaron diferencias significativas $(p<0.0001)$ respectivamente tanto a partir de datos mitocondriales $(0.228)$ como de microsatélites (0.095), aunque la pérdida de variabilidad en FAR podría estar asociada al error de muestreo al establecer el lote de reproductores a partir de peces salvajes, los resultados de la inferencia de parentesco sugieren que la mayor parte de esta pérdida podría estar relacionada con la varianza reproductiva entre los miembros de la generación parental, particularmente entre las hembras.

Palabras clave: Solea senegalensis, variabilidad genética, región control mitocondrial, loci microsatélite, gestión de reproductores, peces planos, varianza reproductiva.

\section{INTRODUCTION}

Senegalese sole (Solea senegalensis, Kaup, 1858) is a flatfish of high commercial importance that is indistinguishable by consumers from common sole $(S$. solea, Linnaeus, 1758), so it is rated as the same species in marketing statistics (Reig et al. 2000). These two species, however, display marked differences in biological requirements that are important for rearing in captivity, such as spawning timing and temperature tolerance (Imsland et al. 2003). Although interest in farming Senegalese sole intensively in southern Europe dates back to the early 1980 s, it failed to reach successful commercial development (Imsland et al. 2003, Reig et al. 2003). The reasons for this include lack of full control over spawning, poor fry quality and high mortality rates during the weaning stage (Cañavate and Fernández-Díaz 1999; Anguís and Cañavate 2005), all leading to juvenile scarcity for stocking purposes. This problem is compounded by a high incidence of skeletal malformations in post-larvae and juveniles (Gavaia et al. 2002) and of disease outbursts affecting all ontogenetic stages caused by multiple pathogenic agents (Zorrilla et al. 2003). Furthermore, optimization of production has not been possible due to high heterogeneity in growth rates within cultured stocks that result in high body size variance at harvest (Dinis et al. 1999, Flos et al. 2001).

Because losses in genetic variability are known to negatively affect survival and growth (Falconer 1960), a good benchmark during the establishment of breeding programmes is to characterize the genetic composition of wild stocks in order to maintain similar levels of genetic variability in captive populations. Ultimately, this information can be used to prevent inbreeding in captivity and to minimize the potential genetic dilution of natural populations in accidental escapes of hatchery fish, or as part of stock enhancement programmes (Sekino et al. 2002, Fjalestad et al. 2003, Porta et al. 2007), a practice that is being considered as aquaculture industries increase their activity (Cognetti et al. 2006). In addition, the characterization of genetic variation is a prime requirement for marker-assisted selection (MAS) programmes aimed at increasing production (Fjalestad et al. 2003).

Genetic variability between wild and hatcheryreared marine fishes has been compared for several species (Coughlan et al. 1998, Tinti and Piccinetti 2000, Alarcón et al. 2004, Nguyen et al. 2006). Among soles, the characterization of genetic variability has focused primarily on elucidating the genetic popula- tion structure of wild populations of $S$. solea and $S$. senegalensis using allozyme (Exadactylos et al. 1998) and mitochondrial DNA (mtDNA) control region (CR) data (Tinti et al. 2000, Guarniero et al. 2002). In addition, genetic studies have been conducted to clarify the phylogenetic relationships among members of this genus (Tinti et al. 2000, Borsa and Quignard 2001).

Studies of genetic diversity of farmed soles are limited to the characterization of variation in S. solea with allozymes (Exadactylos et al. 1999), and recent studies in S. senegalensis using microsatellite loci by Porta et al. (2006, 2007). These studies revealed substantial reductions in genetic variability in just one generation in stocks composed of $F_{1}$ individuals compared with wild donor populations. Similarly, Sekino et al. (2002) documented a marked reduction in genetic variability in both nuclear DNA (nDNA) and mtDNA in hatchery strains of the flatfish Japanese flounder (Paralichthys olivaceus) compared with wild populations. Because of the high resolution of the hypervariable mtDNA CR nucleotide sequence data, Sekino et al. (2002) were able to conclude that only a small fraction of the stocked females contributed to the reared population.

The goal of this study was to compare the level of genetic variability of a farmed Senegalese sole population with its wild donor population by determining the nucleotide sequence of the hypervariable mtDNA control region I (CR-I), and by characterizing six microsatellite loci. Both mtDNA and microsatellite data were then used to infer sibship relationships within samples. Additionally, this study aimed to perform a preliminary exploration of the genetic relationships between Atlantic and Mediterranean Senegalese sole populations.

\section{MATERIALS AND METHODS}

A total of 160 specimens of S. senegalensis were obtained from the following sources:

1) A farmed sample (FAR, n=116) supplied by an aquaculture operation located in the vicinity of the Ebro River delta (NE coast of Spain) in 2003. These farmed specimens were the $F_{1}$ progeny of a broodstock kept at the "El Toruño" CICEM research centre on the SW Atlantic coast of Spain. This facility obtains its broodstock from the nearby ponds, which are communicated with the waters of the Cadiz Bay (Anguís and Cañavate 2005).

2) A wild Mediterranean sample (MED, $n=18$ ) caught by local fishermen from the Mediterranean fishing harbor of Torredembarra, located north of the Ebro river, along the NE coast of Spain, in January 2004. 
3) A wild Atlantic sample (ATL, $n=26$ ) captured in December 2005 by local fishermen from the Atlantic fishing harbours of Barbate and Sanlúcar de Barrameda, both in the Gulf of Cadiz, along the SW coast of the Iberian Peninsula. These two Atlantic locations were pooled to increase the sample size, taking into account that their geographical proximity and the lack of geographic differentiation shown for other flatfish species (Borsa et al. 1997).

Tissue samples consisted of white skeletal muscle obtained either by needle biopsy (Sánchez et al. 2003) from farmed fish or by necropsy from the wild fish samples. Tissue was preserved in $96 \%$ ethanol until assayed in the laboratory. Total DNA was extracted overnight using the modified version of the Proteinase K-ethanol precipitation method without organic extractions described by Greig (2000).

\section{Characterization of the mtDNA Control Region-I (CR-I)}

The entire mtDNA CR-I of 110 Senegalese soles (74 FAR, 18 MED and 18 ATL) was amplified using the primer L15998-Pro (5' TACCCCAAACTCCCAAAGCTA 3') (NCBI accession number AY270154; Alvarado Bremer et al. 1995) and the universal H-strand primer H00598-Phe (5' GCATCTTCAGTGCTATGCTTT 3'; Vu, 1997). All polymerase chain reactions (PCR) were carried out in $12.5 \mu \mathrm{l}$ volumes containing $1.25 \mu \mathrm{l}$ of 10X PCR buffer (Invitrogen, $20 \mathrm{mM}$ Tris- $\mathrm{HCl}$, pH 8.4, $50 \mathrm{mM} \mathrm{KCl}), 2.5 \mathrm{mM}$ $\mathrm{MgCl}_{2}, 0.2 \mathrm{mM}$ of each primer, $0.2 \mathrm{mM}$ of each dNTP, 0.31 U of Taq polymerase (Invitrogen, Platinum Taq) and $1 \mu \mathrm{l}$ of template DNA, except for ATL samples, which were amplified using Sigma JumpStart Taq DNA polymerase and its corresponding buffer (100 $\mathrm{mM}$ Tris- $\mathrm{HCl}, \mathrm{pH} 8.3,500 \mathrm{mM} \mathrm{KCl}$ ).

Amplicons were sequenced with L15998 primer using the dideoxy terminators method (Sanger et al. 1977) and the ABI Prism BigDye Terminator Cycle Sequencing Ready Reaction Kit (Applied Biosystems, Foster City, CA). Nucleotide sequences were read using an ABI Prism 310 Genetic Analyzer. Nucleotide sequences were visualized in Chromas 1.45 (Technelysium Pty Ltd) and multiple sequence alignments were manually optimized in BioEdit (Hall, 1999), using the orthologous sequence of common sole (NCBI accession number AF034262) as reference.

The number of haplotypes (M), haplotypic diversity (h) (Nei and Tajima, 1981) and nucleotide diversity $(\pi)$ (Nei 1987) and mean number of pairwise differences (mPD) (Nei and Li, 1979) were estimated with ARLEQUIN 3.5 (Excoffier and Lischer 2010). The proportion of variance distributed between samples $\left(F_{S T}\right)$ was estimated by an analysis of the molecular variance (AMOVA) (Excoffier et al. 1992) as implemented in ARLEQUIN. Significance levels were determined by conducting a non-parametric permutation procedure 1023 times.
TABLE 1. - PCR conditions for six polymorphic microsatellite loci used to characterize three samples of Senegalese sole.

\begin{tabular}{lccc}
\hline Locus & $\mathrm{A}_{\mathrm{T}}\left({ }^{\circ} \mathrm{C}\right)$ & PCR & Co-amplified locus \\
\hline Sol12D & 56 & Simplex & \\
Sol13B & 60 & Multiplex & SolCA13 \\
SolCA13 & 60 & Multiplex & Sol13B \\
Sol14 & 50 & Simplex & \\
Sol19A & 60 & Multiplex & SolMII \\
SolMII & 60 & Multiplex & Sol19A \\
\hline
\end{tabular}

$A_{T}=$ annealing temperature of the PCR. $P C R=$ whether polymerase chain reaction amplified a single locus (simplex) or two loci (multiplex). Co-amplified locus $=$ locus amplified in the same multiplex reaction.

A statistical parsimony cladogram incorporating haplotype frequencies was estimated in TCS (Clement et al. 2000), where the probability of parsimony is calculated for DNA pairwise differences until the probability exceeds $95 \%$. The number of mutational differences associated with this probability is then the maximum number of mutational connections justified by the parsimony criterion. This approach allows genealogical relationships to be observed as a network instead of a tree, depicting loops wherever such relationships cannot be unambiguously resolved.

\section{Microsatellite loci}

Six microsatellite loci, described for $S$. senegalensis by Porta and Álvarez (2004), were amplified for all the 160 fish, using fluorescently labelled primers (IDT DNA and Applied Biosystems). All PCR reactions were performed following the same procedure as the one described for the mtDNA CR-I, and four reactions were necessary for genotyping each individual: 2 simplex PCR and 2 multiplex PCR with 2 markers each. In all cases, PCR volume was adjusted for a final reaction volume of $12.5 \mu \mathrm{l}$. The amplified loci, annealing temperature of each reaction, as well as if amplification was on a simplex or multiplex PCR (with the corresponding multiplex pair for each locus), are presented in Table 1. All PCR products were mixed and diluted in 1:30 bi-distilled water, and denatured in highly deionized formamide at $95^{\circ} \mathrm{C}$ for $2 \mathrm{~min}$. Molecular weight of the different fragments was assessed through capillary electrophoresis in an ABI Prism 310 Genetic Analyzer and analyzed in Genescan 3.7 and GeneMapper 4.0 (Applied Biosystems) using GENESCAN ${ }^{\mathrm{TM}_{-}}-500$ TAMRA $^{\mathrm{TM}}$ as the molecular weight marker.

Genetic variability estimators, including observed heterozygosity (Ho) and expected heterozygosity (He), $F_{I S}$ and $F_{S T}$ for each population, as well as the assessment of the Hardy-Weinberg equilibrium for each locus within each population, were performed in Genepop 3.34 (Raymond and Rousset, 1995). Allelic richness and private allelic richness were calculated through statistic rarefaction to compensate for the bias in sample size in HP-Rare 1.0 (Kalinowski 2005). Genic and genotypic differentiation, as well as linkage disequilibrium between loci, was estimated in Genep- 
TABLE 2. - Solea senegalensis mtDNA CR-I haplotypes (Ssen\#) defined by the variable nucleotide positions (numbers above sites), their corresponding NCBI's GenBank accession numbers, and relative frequencies in farmed (FAR), wild Atlantic (ATL) and wild Mediterranean (MED) sole. Sampling details in Materials and Methods. Identity with sequence Ssen001 is indicated by dots (.), and ambiguous nucleotides positions by the letter $\mathrm{N}$.

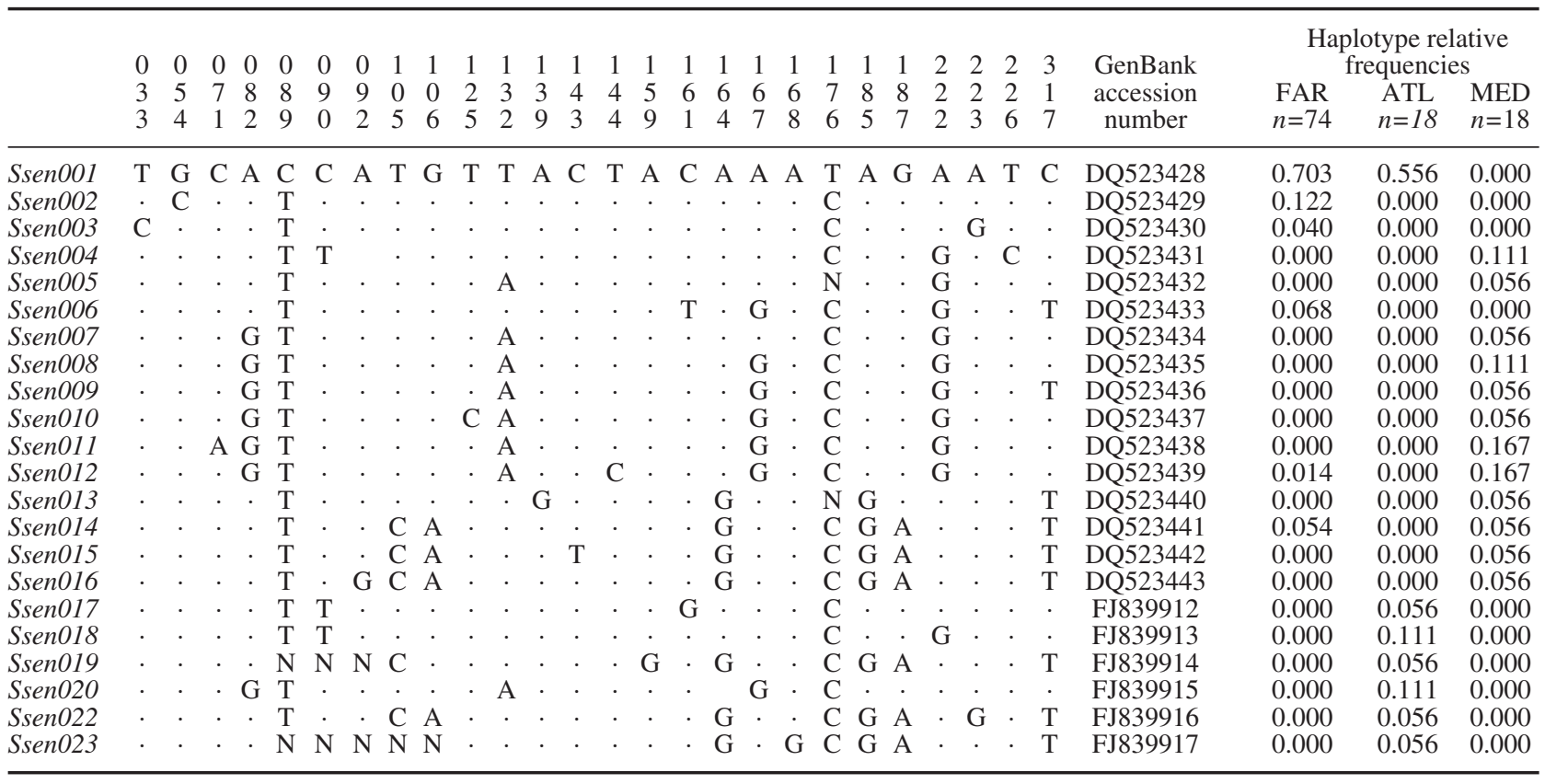

op 3.4 (Markov chain: 1000 batches, 10000 iterations). Average gene diversity was estimated in ARLEQUIN 3.5. All loci were checked for null alleles with MicroChecker 2.2.3 (Van Oosterhout et al. 2004). Genetic differentiation among populations was also assessed using a locus-by-locus AMOVA with the number of alleles as distance, as implemented in ARLEQUIN 3.5.

\section{Parentage and sibship inference}

As the exact composition of the original broodstock was unknown, the number of parental individuals for FAR was inferred using COLONY 2.0 (Wang, 2004). Parental genotypes were inferred through maximum likelihood, assuming polygamous mating for both males and females, using the allele frequencies observed in the donor sample (ATL). The likelihood that each pair of individuals was or was not related was also estimated. In these analyses those individuals that did not share the same mtDNA CR-I haplotype were excluded as potential maternal siblings. Similar analyses were performed for ATL and MED samples, using the respective observed allele frequencies for each sample.

Average individual maximum likelihood estimates of relatedness for each sample were computed on MLRELATE (Kalinowski et al. 2006). Mean variability estimators were compared among samples through a Student $t$ test $(\alpha=0.05)$ with the Welch correction for 2 independent samples, except when a Shaphiro-Wilk test failed to detect normality within the sample. In such cases, a non-parametric Wilcoxon rank sum test with continuity correction was used instead. All tests were performed on R (R Development Core Team, 2010).

\section{RESULTS}

\section{mtDNA CR-I analysis}

In total, 412 base pairs (bp) of nucleotide sequence of the mtDNA CR-I were determined for 74 farmed and 36 wild Senegalese sole (Table 2). A total of 26 segregating sites (K), 12 of which were parsimonyinformative, defined 22 distinct Senegalese sole CR-I haplotypes. Haplotype frequencies, the number of segregating sites, and the NCBI's GenBank accession numbers for each sample are also included in Table 2.

Genetic variation was lower in the farmed sample than in the wild Atlantic sample. Accordingly, the probability of selecting two different haplotypes from a random pair was higher in ATL $(h=0.69 \pm 0.114)$ than in FAR $(h=0.49 \pm 0.066)$. In FAR $83 \%$ of the sample was accounted for by the two most common haplotypes (Ssen001 and Ssen002), with Ssen001 accounting for $70 \%$ and $56 \%$ of FAR and ATL, respectively, but absent from MED (Table 2). Estimates of nucleotide di-

TABLE 3. - Genetic variability estimators from the analysis of 412 bp of the mtDNA Control Region-I sequences for three samples of Senegalese sole.

\begin{tabular}{lcccccc}
\hline & $\mathrm{N}$ & $\mathrm{M}$ & $\mathrm{Mp}$ & $h$ & $\pi$ & $\mathrm{mPD}$ \\
\hline FAR & 74 & 6 & 3 & $0.489 \pm 0.067$ & $0.006 \pm 0.004$ & $2.467 \pm 1.35$ \\
ATL & 18 & 7 & 6 & $0.693 \pm 0.114$ & $0.009 \pm 0.006$ & $2.771 \pm 1.54$ \\
MED & 18 & 12 & 10 & $0.948 \pm 0.033$ & $0.030 \pm 0.016$ & $11.963 \pm 5.68$
\end{tabular}

Sample acronyms as in Table 2. N, number of sequenced individuals; M, number of different haplotypes; Mp, number of private haplotypes; $h$, haplotypic diversity; $\pi$, nucleotide diversity; $\mathrm{mPD}$, mean number of pairwise differences. 
TABLE 4. $-F_{S T}$ values of the analysis of the molecular variance (AMOVA) for three Senegalese sole populations.

\begin{tabular}{llllllll}
\hline a) & FAR & ATL & MED & b) & FAR & ATL & MED \\
\hline FAR & 0 & 0.024 & $0.395^{* *}$ & FAR & 0 & - & - \\
ATL & $0.127^{* *}$ & 0 & $0.228^{* *}$ & ATL & $0.053^{* *}$ & 0 & - \\
MED & $0.055^{* *}$ & $0.095^{* *}$ & 0 & MED & $0.053^{* *}$ & $0.054^{* *}$ & 0 \\
\hline
\end{tabular}

FAR, farmed fish; ATL, wild Atlantic fish; MED, wild Mediterranean fish. a) Above diagonal: $\Phi_{S T}$ values corresponding to the AMOVA of mitochondrial DNA data. Below the diagonal: $F_{S T}$ values corresponding to the AMOVA of microsatellite data including all six studied markers. b) Below the diagonal only: $F_{S T}$ values corresponding to the AMOVA of microsatellite data excluding locus Sol14. ${ }^{*} P<0.01 ; * *$ $P<0.001$.

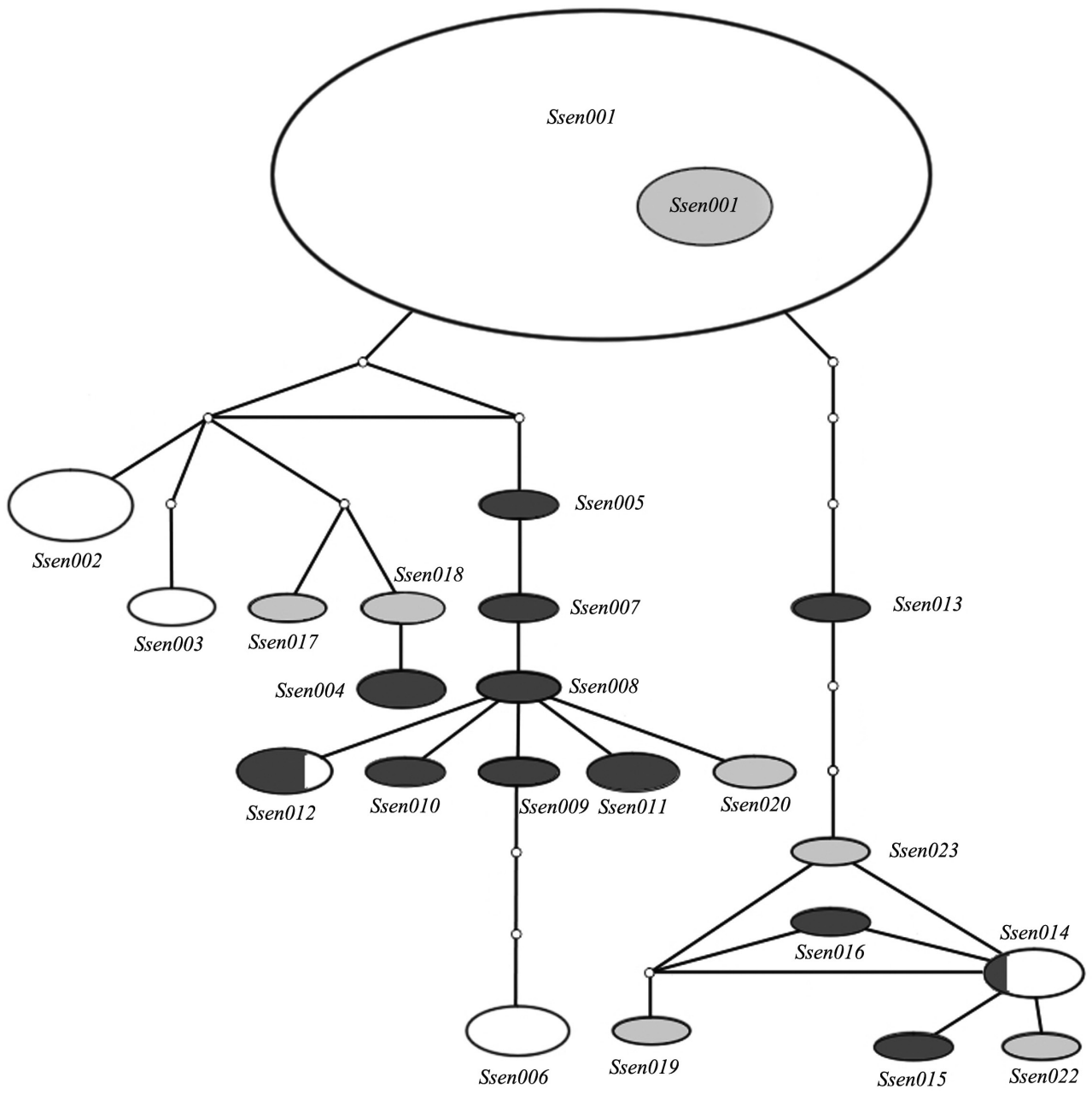

FIG. 1. - Parsimony network estimated in TCS v1.21 for FAR, ATL and MED haplotypes (FAR = farmed Atlantic sample; ATL = wild Atlantic sample; MED = wild Mediterranean sample). The area of the ellipsoids is proportional to the frequency of each haplotype within the pooled populations. Un-sampled or non-existent nodes are represented by small white dots. White, grey and black ellipsoids stand for FAR, ATL and MED, respectively.

versity and mean number of pairwise differences were also higher in ATL than in FAR (Table 3). An AMOVA comparing FAR and ATL identified most of the genetic variation within populations, with only $2.35 \%$ of the mtDNA variance corresponding to non-significant differences between these two populations (Table 4).

There were substantial differences in genetic variability between wild Atlantic (ATL) and wild Mediterranean fish (MED) samples (Table 3), with a higher diversity in MED $(h=0.95 \pm 0.03)$ than in ATL $(h=0.69 \pm 0.11)$. Similarly, estimates of nucleotide diversity and mean number of pairwise differences were three and four times higher in MED than in ATL (Table 3). There were 12 different haplotypes in MED, ten of these private and including Ssen011, one of two most common haplotypes in this population at $16.7 \%$, with the other (Ssen012) shared with FAR (Table 2). An AMOVA of mtDNA CR-I data of the two wild samples revealed that roughly one fourth $\left(\Phi_{S T}=0.228\right.$; $P<0.0001)$ of the total genetic variability corresponded to differences between ATL and MED (Table 4), with the rest of the variance within samples. 
TABLE 5. - Genetic variability estimators for six polymorphic microsatellite loci used to characterize the three samples of Senegalese sole.

\begin{tabular}{llcccccccc}
\hline Locus & Sample & $\mathrm{N}$ & \#alleles & \#private alleles & $\mathrm{A}_{\mathrm{g}}$ & Private $\mathrm{A}_{\mathrm{g}}$ & $\mathrm{He}$ & Ho & Fis \\
\hline Sol12D & FAR & 114 & 5 & & 4.9 & 0.01 & 0.73 & 0.70 & $0.0413^{* *}$ \\
& ATL & 26 & 6 & 1 & 5.3 & 0.77 & 0.72 & 0.58 & 0.2013 \\
\multirow{5}{*}{ Sol13B } & MED & 18 & 5 & 1 & 5.0 & 1.00 & 0.74 & 0.72 & 0.0286 \\
& FAR & 115 & 14 & 1 & 9.2 & 0.22 & 0.85 & 0.90 & $-0.0684^{* *}$ \\
& ATL & 25 & 11 & & 10.0 & 1.27 & 0.89 & 0.96 & -0.0557 \\
SolCA13 & MED & 18 & 90 & & 8.9 & 0.91 & 0.87 & 0.94 & -0.0804 \\
& FAR & 113 & 10 & & 7.8 & 0.61 & 0.80 & 0.75 & $0.0623 * *$ \\
& ATL & 26 & 13 & 2 & 11.1 & 2.32 & 0.89 & 0.85 & 0.0542 \\
Sol14 & MED & 18 & 9 & 1 & 8.9 & 1.90 & 0.84 & 0.83 & 0.0135 \\
& FAR & 111 & 5 & 1 & 3.2 & 0.15 & 0.41 & 0.42 & -0.0535 \\
& ATL & 26 & 6 & 1 & 5.7 & 0.94 & 0.56 & 0.35 & $0.3882^{*}$ \\
Sol19A & MED & 18 & 7 & 2 & 6.9 & 2.11 & 0.69 & 0.72 & -0.0400 \\
& FAR & 114 & 7 & & 5.3 & 0.12 & 0.73 & 0.85 & -0.1669 \\
& ATL & 26 & 7 & 1 & 6.8 & 1.96 & 0.82 & 0.73 & 0.1071 \\
SolmII & MED & 17 & 6 & & 6.0 & 1.57 & 0.76 & 0.82 & -0.0900 \\
& FAR & 113 & 9 & 2 & 6.8 & 0.54 & 0.78 & 0.85 & -0.0909 \\
& ATL & 26 & 7 & & 7.0 & 0.00 & 0.86 & 0.88 & -0.0305 \\
& MED & 17 & 7 & & 7.0 & 0.03 & 0.83 & 0.71 & 0.1504 \\
\hline
\end{tabular}

FAR, farmed fish; ATL, wild Atlantic fish; MED, wild Mediterranean fish; N, number of individuals genotyped for each locus; Ag, allelic richness; Ho, observed heterozygosity; He, expected heterozygosity.* $P<0.01 ; * * P<0.001$

The relationship among the 22 haplotypes is depicted with a genetic network obtained by statistical parsimony (Fig. 1). Haplotypes of both farmed and wild samples are interspersed throughout the branches, and include one haplotype (SsenO01) shared between ATL and FAR, and two haplotypes (SsenO12 and SsenO14) shared between FAR and MED.

\section{Microsatellite data analysis}

Analysis of a sample of 160 Senegalese sole from three populations (116 FAR, 26 ATL and 18 MED) identified a total of 64 alleles for the six studied loci, ranging from 7 to 14 alleles per locus, with a mean value of 10.6 alleles per locus. The mean number of private alleles per locus was 1.3. Mean allelic richness was 7.0 and mean private allelic richness was 0.9 . Mean values of expected and observed heterozygosity were 0.77 and 0.75 , respectively. The values of genetic variability estimators for all three samples are shown in Table 5.

The mean values for expected and observed heterozygosity in FAR were 0.72 and 0.75 , showing significant departures from the Hardy-Weinberg equilibrium at three loci. Sol12D and SolCA13 showed heterozygote deficiency, while Sol13B showed heterozygote excess. $F_{I S}$ values for these loci were significant, although low (between -0.07 and 0.06). Significant linkage disequilibrium $(P<0.05)$ was detected between all pairs that included Soll3B or Sol19A, and also between SolCA13 and Soll4, and between SolCA13 and SolMII. Accordingly, in FAR 11 out of the 15 possible pairs of loci were linked. No null alleles were detected in FAR.

Observed indices of genetic variability for FAR are similar to those obtained for its donor population (ATL), including similar values of allelic richness and allele size ranges. FAR and ATL had a total of 50 alleles each, accounting respectively for $78.1 \%$ of all the polymorphism observed in the pooled sample of the three localities. Although average allelic richness was lower in FAR $(6.2 \pm 2.16)$ than in ATL $(7.7 \pm 2.35)$, and in MED (7.1 \pm 1.56$)$, these estimates were not significantly different from each other (Student $t$ test; $P<0.05)$. However, mean private allelic richness was significantly higher (Student $t$ test; $P<0.05$ ) in ATL (1.21) than in FAR (0.28). Mean values of expected and observed heterozygosity were 0.79 and 0.73 , respectively, with only one microsatellite locus (Sol14) significantly departing from the Hardy-Weinberg equilibrium in ATL, where a high (0.388) and significant $F_{I S}$ value $(P<0.01)$, indicative of heterozygote deficit, was detected. Null alleles were detected solely at Sol14 in ATL. No linkage disequilibrium was found in ATL among any of the loci pairs $(P<0.05)$.

MED, the smallest sample analyzed, showed similar allelic richness to that in FAR and ATL. A total of 43 alleles were found in MED, accounting for $67.2 \%$ of the total allele count for the three localities, with a mean of 7.1 alleles per locus. In addition, mean private allelic richness for MED was significantly higher (1.25; Student $t$ test; $P<0.05$ ) than for FAR, but not significantly different from ATL. Mean expected and observed heterozygosity values for MED equalled 0.79 , with no significant departures from the HardyWeinberg equilibrium or significant linkage disequilibrium among loci pairs $(P<0.05)$. No null alleles were detected in MED.

Average gene diversities over loci using the number of different alleles as distance were similar among ATL (0.78), FAR (0.69) and MED (0.79). Additionally no differences were observed for mean expected heterozygosity nor expected heterozygosity among all three samples (Student $t$ test; $P>0.05$ ). Several alleles in FAR occurred at higher frequencies than in ATL (Fig. 2), including alleles 149 and 161 in Soll3B, allele 229 in Sol14, and alleles 128 and 132 in Sol19A, all rare in ATL (Fig. 2). The reciprocal condition was observed, specifically, allele 226 in Soll4 accounted for $65.4 \%$ in ATL and only $0.5 \%$ in FAR (Table 5). 
a)

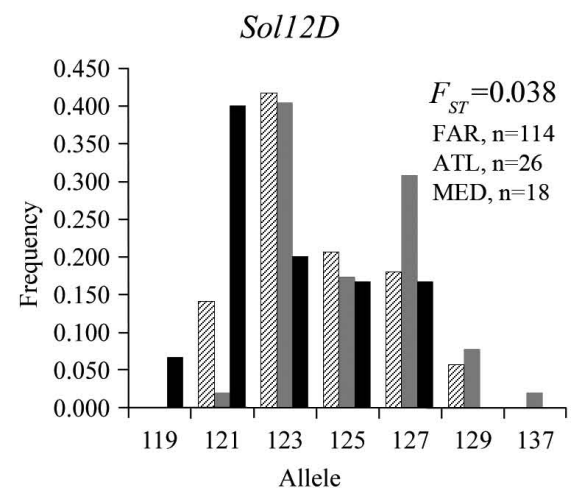

c)

SolCA13

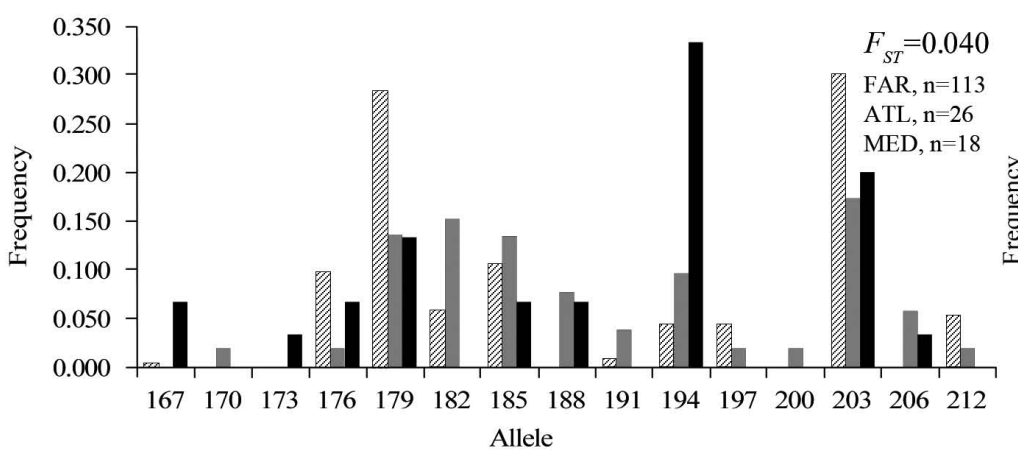

e)

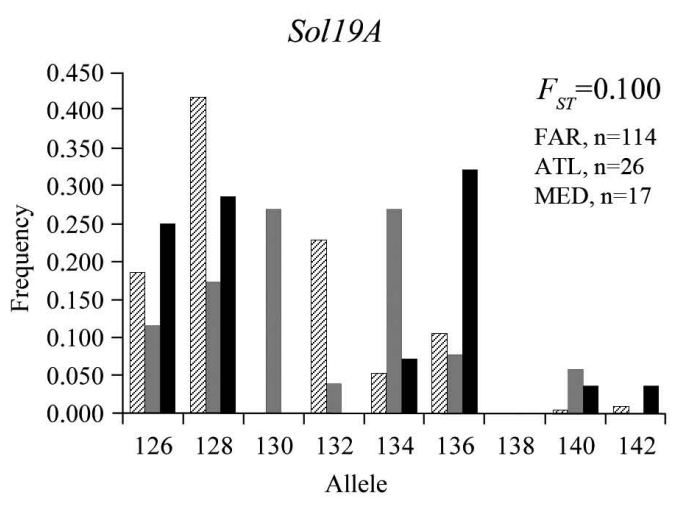

f) b)

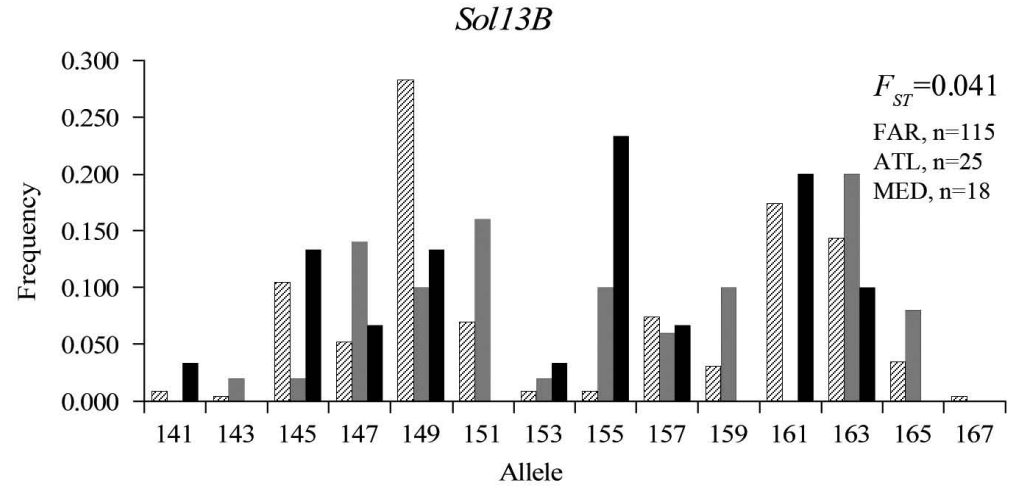

d)
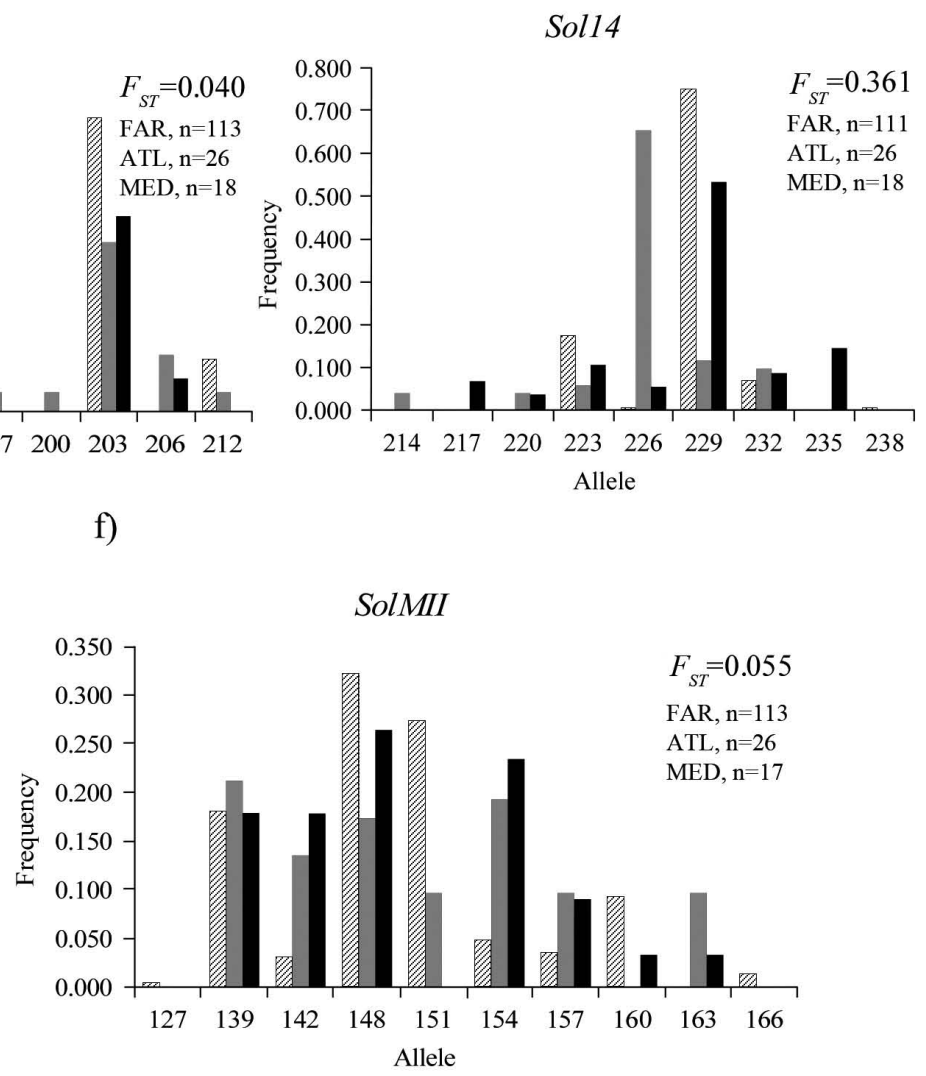

FIG. 2. - Allele frequencies for each of the six microsatellite loci characterized in this study. a) Sol12D, b) Sol13B, c) SolCA13, d) Sol14, e) Sol19A and f) SolMII for the three Senegalese sole samples: FAR (pattern bars); ATL (grey bars); MED (black bars). The number (n) of individuals per sample characterized for each locus is given. On each x-axis, the allele sizes (bp) for each locus, and on each y-axis the corresponding relative frequency. $F_{S T}$ for each locus estimated among the three samples.

Multilocus AMOVA identified FAR and ATL as the sample-pair with the highest proportion of variation between groups, with a $F_{S T}$ value of $0.127(P<0.0001)$ compared with the $F_{S T}$ for FAR and MED and for ATL and MED at 0.055 and 0.095 , respectively (Table 4). $F_{S T}$ values by locus inferred from the AMOVA among all three samples ranged from 0.038 for Sol12D to a substantially higher value of 0.361 for Soll4 (Fig. 2). A locus-by-locus AMOVA between all sample-pairs yielded $F_{S T}$ values that were four to 50 times larger for Soll4 than for other loci (data not shown), reaching
0.298 for ATL to MED and 0.492 for ATL to FAR, compared with 0.070 between FAR and MED. Excluding Sol 14 from the multi-locus AMOVA yielded considerably lower $F_{S T}$ values in all comparisons involving ATL (Table 4).

\section{Parentage, sibship inference and relatedness}

A total of 18 male and 16 female parental genotypes were inferred in the FAR sample. The combination of these inferred broodstock genotypes could yield a total 
of 58 full-sib groups or families (220 full-sib dyads), ranging from two to 15 full-sib individuals per family, and up to 750 half-sib dyads. All the offspring could be grouped in a single cluster (understanding as a cluster all offspring that, regardless of whether or not they share a parent, are still linked in a pedigree).

Three of the inferred female genotypes were identified as particularly prolific, accounting for $50 \%$ of the offspring and producing 22, 19 and 16 offspring. By contrast, the remaining females contribution ranged between one and 12 descendants, with an average of 4.5 offspring per female. Furthermore, FAR specimens sharing haplotype Ssen001 $(\mathrm{n}=52)$ could have been generated by seven females, with the two most prolific accounting for 79\% (41/52) of those individuals. These two females could have mated with up to 13 and four different males, respectively. The reproductive variance in paternal contribution was less pronounced, with only one inferred male as prolific as the dominant maternal genotypes, potentially siring 19 individuals. The remaining males sired on average 5.7 individuals, with a range of between 2 and 13 offspring per male, a contribution comparable with that of non-dominant females.

The whole ATL sample could have been bred by the 11 male and 13 female inferred parental genotypes, which could be grouped into four different clusters, although three of them included only one individual, and revealed two full-sib individuals as well as up to 24 half-sib families (47 half-sib dyads). A minimum of four females could have produced those individuals carrying haplotype Ssen 001 , corresponding to about $46 \%$ of the sample.

Sibship and parental inference for MED identified up to 15 possible half-sib families (15 half-sib dyads) as the product of the inferred genotypes of 7 males and 14 females, grouping all the offspring into six clusters. No full sibs were found in MED and only two fish, sharing haplotype (Ssen008), could be grouped as maternal siblings. Mating of different parents likely produced the rest of the individuals in that sample.

A parental variability index $\left(P_{V}\right)$ that takes into account the differences in size between samples is proposed as the ratio between the number of inferred parental genotypes and the number of candidate offspring as follows:

$$
P_{V}=\left[\left(N_{M}+N_{P}\right) / 2\right] * 1 / N_{O}
$$

where $N_{M}$ stands for the number of maternal genotypes, $N_{P}$ for the number of paternal genotypes and $N_{O}$ for the number of the offspring. An offspring in which each individual is bred by a single couple of parental genotypes would have an index of $P_{V}=1$, indicating the highest level of parental variability. Accordingly, $P_{V}$ values for FAR, ATL and MED calculated through the inferred number of parental genotypes in COLONY were $0.150,0.462$ and 0.583 , respectively.
Mean individual relatedness within samples $(r)$ was $0.06 \pm 0.101$ for both ATL and MED, and $0.11 \pm 0.179$ for FAR. No significant differences of these values were found between ATL and MED, but the relatedness value for the farmed sample was significantly higher than for both wild populations (Wilcoxon rank sum test; $P<0.001)$.

\section{DISCUSSION}

The analysis of $412 \mathrm{bp}$ of nucleotide sequence of the mtDNA CR-I from two wild samples and a farmed $F_{1}$ sample of Senegalese sole revealed a substantial loss of genetic variability in one generation of aquaculture rearing, as shown by haplotypic diversity values and the haplotypic composition of each sample. FAR and ATL shared only haplotype Ssen001, the most common haplotype in both populations, respectively at a frequency of $70 \%$ and $56 \%$ but absent from MED. Similarly, the second most common haplotypes in FAR (Ssen002) and ATL (Ssen018) were private to each sample and absent in MED. It should be noted that an AMOVA using mtDNA CR-I data failed to find significant differences between ATL and FAR, presumably because of the high frequency of haplotype Ssen001 in these samples. With the exception of Ssen001, the rest of ATL haplotypes were private to that sample.

Lower estimates of mtDNA diversity have been reported in farmed flatfish compared with wild populations. In Japanese flounder, Sekino et al. (2002) found an average haplotypic diversity of 0.761 for three farmed samples compared with 0.998 for a wild sample. The value of haplotypic diversity for the wild ATL sample reported here is lower than those of farmed Japanese flounder. Although the lower mtDNA variability in FAR could have been caused by sampling error during the establishment of the broodstock, it could also be the result of the differential reproductive performance among parents, as suggested in this species by Porta et al. (2007). By contrast, the value of haplotypic diversity of MED was higher $(h=0.948)$, and while this estimate is lower than the value reported in wild Japanese flounder, it is similar to haplotypic diversity values reported for the wild Mediterranean populations of albacore tuna, Thunnus alalunga $(h=0.961 \pm 0.018)$, (Viñas et al. 2004) and swordfish, Xiphias gladius, ( $h=0.942 \pm 0.009$ ) (Alvarado Bremer et al. 2005).

Consistent with the reduction in mtDNA variability, private allelic richness was an indicator of allele loss in FAR, being significantly lower than in both wild samples (Table 5). Additionally, Soll4 showed significant homozygote excess in ATL due to this high proportion of allele 226, which was likely responsible for the high fixation index of this locus among populations. Porta and Álvarez (2004) also reported a significant excess of homozygotes at this locus for a hatchery stock. Since the analysis with Micro-Checker strongly suggested the presence of null alleles at this locus, it was excluded from the analyses, resulting in a reduction in 
half of the $F_{S T}$ values for the comparisons that involved ATL, while at the same time lowering the p-value for comparisons of private allelic richness to 0.07 , close to the threshold of significance adopted here. These $F_{S T}$ values calculated without Sol14 explain the apparent contradiction of a larger differentiation between FAR and ATL as opposed to MED and ATL that came from geographically more distant locations. Altogether, the differences in allele frequency resulted in significant allelic and genotypic differentiation between FAR and ATL. Despite these differences, the values of microsatellite heterozygosity were similar in FAR (0.75), ATL (0.73) and MED (0.79), with these values comparable to the average heterozygosity $(0.79 \pm 0.19)$ reported by DeWoody and Avise (2000) for a pool of 12 marine fish species. However, all three Senegalese sole samples showed a low average value of allelic richness per locus, ranging from 6.2 in FAR to 7.7 in ATL, compared with the average value of $19.9 \pm 6.6$ for marine fishes (DeWoody and Avise 2000). Porta et al. (2007) reported an average allele number for eight microsatellites loci ranging between 7.9 and 16.7, depending on the size of the sample and whether the fish were hatcheryreared or wild. However, of the eight loci analyzed by Porta et al. (2007), only four were characterized in here (Sol13B, Sol19A, SolCA13 and SolMII). Restricting the comparison to these four loci yields similar ranges in the average number of alleles, between 7.5 and 12.5 for Porta et al. (2007) and 7.8 and 10.0 for this study.

Mean relatedness was higher in the cultured sample than in the wild samples. This is consistent with the data presented above for both mtDNA and microsatellite loci, and with relatedness values found in many reared fish species, including Senegalese sole (Porta et al. 2007). It is interesting to observe that while ATL showed lower haplotypic diversity than MED, both samples had similar mean relatedness and gene diversity values estimated from nDNA data. Apparent discrepancies between variability levels detected with microsatellite loci and mtDNA CR-I analysis have already been described by Alarcón et al. (2004) in gilthead sea bream (Sparus aurata) and were attributed to presence of rare haplotypes in high frequencies. The authors suggested that this pattern could be explained by drift in subdivided populations. In the present study, the small sizes of the wild samples, together with their restricted geographic origin, precludes reaching a definitive conclusion regarding this issue, but suggests the need for further studies.

Biases in both mtDNA haplotype and nDNA allele frequencies in farmed fish compared with the wild population of origin are not uncommon (Coughlan et al. 1998, Alarcón et al. 2004; Aho et al. 2006). Such biases result from random sampling error of the wild population when broodstocks are established using a small number of individuals (founder effect), together with the ensuing genetic drift experienced by successive generations of inbreeding in small effective size populations. The founder effect is particularly important in the interpretation of the results of this study, as the performance of hatchery-reared individuals of Senegalese sole as broodstock has been marginal. Accordingly, it is customary to utilize only wild-caught individuals as broodstock in aquaculture operations of this species, including the broodstock at "El Toruño" that produced FAR. A biased haplotypic profile in FAR would be expected exclusively from such a founder event even if all individuals in the broodstock contributed equally to this $\mathrm{F}_{1}$. However, Porta et al. (2006) reported substantial losses in genetic variability at eight microsatellite loci in three Senegalese sole broodstock groups, two of which were $F_{1}$ progenies. Specifically, these authors found that alleles that were common in the broodstock were absent in the progeny, suggesting a large variance in reproductive success among potential parents. Such biases in parental contribution have been reported in other flatfishes in aquaculture operations. Blonk et al. (2009) showed that out of two S. solea broodstocks consisting of 28 and 20 individuals only five or fewer parental pairs, respectively, produced more than half of the total progeny. Similarly, only $25 \%$ of the females in two strains of Japanese flounder apparently contributed to the offspring of two strains founded by 50 and 30 candidate female parents (Sekino et al. 2002). The high linkage disequilibrium observed between microsatellite loci in FAR could also be related to possible non-random mating or the bottlenecks that occur in aquaculture breeding in communal tanks where fish mating is not fully controlled, and thus concordant with the results from Porta and Álvarez (2004) and Porta et al. $(2006,2007)$ regarding important biases in the expected allele combinations of $\mathrm{F}_{1}$ generations.

In this study, estimates of reproductive variance among members of the broodstock were assessed by estimating the maternal contribution from the highly informative mtDNA CR-I sequence data, in combination with sibship and parental inference from microsatellite data. Since six mtDNA CR-I haplotypes were identified among 74 FAR individuals, it follows that the maternal stock consisted of a minimum of six females. Although the exact number of parents that produced the $F_{1}$ analyzed in this study is unknown, studies carried out at the same experimental hatchery (Cañavate and Fernández-Díaz 1999, Anguís and Cañavate 2005), suggest that between 8 and 15 females and 7 and 10 males were used to establish the broodstock at this operation. Given that with the exception of Ssen001, present in ATL at 56\% and in FAR at $70 \%$, no other haplotype was shared between FAR and ATL, it is plausible to assume that these non-shared haplotypes do not occur at a high frequency in the wild. In fact, excluding the common haplotype Ssen001 from ATL increased the probability of sampling a different haplotype from 0.693 to 0.929 , a value of $h$ similar to that of MED ( $h=0.948)$. Thus, each of the fish in FAR carrying a distinct haplotype, except those carrying Ssen001, might have been produced by only five dams. 
Incorporating the mtDNA CR-I data in the results from COLONY identifies seven females producing the $\mathrm{F}_{1}$ individuals carrying haplotype Ssen001. Thus, no fewer than 12 females in the parental stock produced FAR. However, inference of parentage and sibship indicates that 16 females account for all the offspring analyzed in FAR. Thus, in addition to the seven females in the broodstock sharing Ssen001, three had to share Ssen002, two Ssen003 and three Ssen006. These estimates of the number of females in the original broodstock are consistent with the higher estimate of 15 females recalled to have been used to establish the original operation at "El Toruño". These results are particularly revealing of the reproductive variance associated with each sample. While in FAR a total of 58 full-sib groups were identified, with 2-15 full sibs per family, in ATL only two full-sib individuals were identified and none in MED. Such dramatic differences in the level of inferred sibship among samples is most likely the result of the large variance in reproductive success among members of the original broodstock, particularly among females, with the four most prolific dams producing $60 \%$ of fish in FAR. The parental variability index also underlines the variability loss of the FAR sample compared with the donor sample $\left(P_{V}\right.$ $=0.462$ for ATL and 0.150 for FAR). It thus appears that the variance in reproductive success among breeders is an important factor responsible for loss of genetic variability among the offspring, and confirming results by Sekino et al. (2002) and Porta et al. (2006, 2007).

Phylogeographic studies of common sole characterizing the mtDNA Control Region revealed geographic isolation among samples within the central Mediterranean (Guarniero et al. 2002). Although the present study is the first to assess the genetic variability of Senegalese sole across basins using mtDNA CR-I data, caution should be used in the interpretation of the results because of the small sample sizes and limited sampling coverage. Nevertheless, the particularly pronounced mtDNA differentiation recorded here between the two wild populations from different basins (ATL and MED) is worth noting. There were nearly twice as many haplotypes in the wild Mediterranean sample as in the wild Atlantic sample, and significant differentiation in both nucleotide diversity values and the mean number of pairwise differences. Values of differentiation between ATL and MED samples with microsatellite data $\left(F_{S T}=0.054\right)$ were similar to the average reported by Ward (1994) for sub-populations of marine fish species $\left(F_{S T}=0.062\right)$. These results are a preliminary approximation for further studies, which should be carried out by increasing the number of sampling locations and the size of the samples to determine the degree of differentiation between Atlantic and Mediterranean Senegalese sole populations. Accordingly, it would be possible to elucidate the presence of a barrier between Atlantic and Mediterranean populations similar to the one found between the west of the Gibraltar Strait and the Ebro Delta-Gulf of Lion in Eu- ropean flounder (Platichthys flesus) using allozymes and mtDNA cytochrome b data (Borsa et al. 1997).

In conclusion, this study documents a loss in genetic variability in a single generation of Senegalese sole rearing, as evidenced by lower values of mitochondrial haplotypic diversity and nuclear diversity of microsatellites in the farmed sample compared with the wild donor population.

The comparison of wild Atlantic and Mediterranean samples in both mitochondrial and microsatellite DNA suggests a limited gene flow between the populations inhabiting these basins, although the exact nature of the isolation mechanism requires further investigation.

Finally, it is clear that an accurate knowledge of the genetic composition of farmed stocks is essential both for maintaining the cultured stocks and for potential future restocking purposes because the genetic composition of the wild populations could be severely affected.

\section{ACKNOWLEDGEMENTS}

This work was funded by the Spanish Ministerio de Ciencia y Tecnología (MCYT AGL2002-00768). JV was a Texas Institute of Oceanography (TIO) post-doctoral fellow at Texas A\&M University at Galveston.

\section{REFERENCES}

Aho T., Rönn J., Piironen J., Björklund M. 2006. Impacts of effective population size on genetic diversity in hatchery reared Brown trout (Salmo trutta L.) populations. Aquaculture 253: 244-248.

Alarcón J., Magoulas A., Georgakopoulos T., Zouros E., Álvarez M. 2004. Genetic comparison of wild and cultivated European populations of the gilthead sea bream (Sparus aurata). Aquaculture 230: 65-80.

Alvarado Bremer J.R., Mejuto J., Baker A.J. 1995. Mitochondrial DNA control region sequences indicate extensive mixing of swordfish (Xiphias gladius L.) populations in the Atlantic Ocean. Can. J. Fish. Aquat. Sci. 52: 1720-1732.

Alvarado Bremer J.R., Viñas J., Mejuto J., Ely B., Pla C. 2005. Comparative phylogeography of Atlantic bluefin tuna and swordfish: the combined effects of vicariance, secondary contact, introgression, and population expansion on the regional phylogenies of two highly migratory pelagic fishes. Mol. Phylogenet. Evol. 36: 169-187.

Anguís V., Cañavate J.P. 2005. Spawning of captive Senegal sole (Solea senegalensis) under a naturally fluctuating temperature regime. Aquaculture 243: 133-145.

Blonk R.J.W., Komen J., Kamstra A., Crooijmans R.P.M.A., Van Arendonk J.A.M. 2009. Levels of inbreeding in group mating captive broodstock populations of Common sole, (Solea solea), inferred from parental relatedness and contribution. Aquaculture 289: 26-31.

Borsa P., Blanquer A., Berrebi P. 1997. Genetic structure of the flounders Platichthys flesus and P. stellatus at different geographic scales. Mar. Biol. 129: 233-246.

Borsa P., Quignard J.P. 2001. Systematics of the Atlantic-Mediterranean soles Pegusa impar, P. lascaris, Solea aegyptiaca, $S$. senegalensis, and $S$. solea (Pleuronectiformes: Soleidae). Can. J. Zool. 79: 2297-2302.

Cañavate, J.P., Fernández-Díaz C. 1999. Influence of co-feeding larvae with live and inert diets on weaning the sole Solea senegalensis onto commercial dry feeds. Aquaculture 174: 255-263.

Clement M., Posada D., Crandall K.A. 2000. TCS: a computer program to estimate gene genealogies. Mol. Ecol. 9: 1657-1660.

Cognetti G., Maltagliati F., Saroglia M. 2006. The risk of "genetic 
pollution" in Mediterranean fish populations related to aquaculture activities. Mar. Pollut. Bull. 52: 1321-1323.

Coughlan J.P., Imsland A.K., Galvin P.T., Fitzgerald R.D., Naevdal G., Cross, T.F. 1998. Microsatellite DNA variation in wild populations and farmed strains of turbot from Ireland and Norway: a preliminary study. J. Fish. Biol. 52: 916-922.

DeWoody J., Avise J. C. 2000. Microsatellite variation in marine, freshwater and anadromous fishes compared with other animals. J. Fish. Biol. 56: 461-473.

Dinis M.T., Ribeiro L., Soares F., Sarasquete C. 1999. A review on the cultivation potential of Solea senegalensis in Spain and in Portugal. Aquaculture 176: 27-38.

Exadactylos A., Geffen A.J., Thorpe J.P. 1998. Population structure of the Dover sole, Solea solea L., in a background of high gene flow. J. Sea. Res. 40: 117-129.

Exadactylos A., Geffen A.J., Thorpe J.P. 1999. Growth and genetic variation in hatchery-reared larval and juvenile Dover sole, Solea solea (L.). Aquaculture 176: 209-226.

Excoffier L., Smouse P., Quattro J. 1992. Analysis of molecular variance inferred from the metric distances among DNA haplotypes: Application to human mitochondrial DNA restriction data. Genetics 131: 150-163.

Excoffier L., Lischer H.E.L. 2010, Arlequin suite ver 3.5: A new series of programs to perform population genetics analyses under Linux and Windows. Mol. Ecol. Res. 10: 564-567.

Falconer D. 1960. Introduction to quantitative genetics. Oliver and Boyd, London.

Fjalestad K. T., Moen T., Gomez-Raya L. 2003. Prospects for genetic technology in salmon breeding programmes. Aquac. Res. 34: $397-406$

Flos R., Reig L., Ambrosio P.P. 2001. Towards the actual transfers of the sole (Solea spp.) to the productive sector. In: Kjorsvik E. Stead S. (eds.), New Species. New Technologies. EAS Special Publication 29: 75-76.

Gavaia P.J., Dinis M.T., Cancela M.L. 2002. Osteological development and abnormalities of the vertebral column and caudal skeleton in larval and juvenile stages of hatchery-reared Senegal sole (Solea senegalensis). Aquaculture 211: 305-323.

Greig T.W. 2000. Partitioning genetic variation in swordfish (Xiphias gladius L.); Analysis of sample variance and population structure. $\mathrm{Ph}$. D. thesis, Univ. South Carolina.

Guarniero I., Franzellitti S., Ungaro N., Tommasini S., Piccinetti C. Tinti F. 2002. Control region haplotype variation in the central Mediterranean common sole indicates geographical isolation and population structuring in Italian stocks. J. Fish. Biol. 60: $1459-1474$

Hall T.A. 1999. BioEdit: a user-friendly biological sequence alignment editor and analysis program for Windows 95/98/NT. Nucl. Acids. Symp. Ser. 41: 95-98.

Imsland A.K., Foss A., Conceição L.E.C., Dinis M.T., Delbare D. Schram E., Kamstra A., Rema P., White P. 2003. A review of the culture potential of Solea solea and S. senegalensis. Rev. Fish. Biol. Fisher. 13: 379-408.

Kalinowski S.T. 2005. HP-Rare: a computer program for performing rarefaction on measures of allelic diversity. Mol. Ecol. Notes. 5: 187-189.

Kalinowski S.T., Wagner A.P., Taper M.L. 2006. ML-Relate: a computer program for maximum likelihood estimation of relatedness and relationship. Mol. Ecol. Notes. 6: 576-579.

Nei M., Li W.H. 1979. Mathematical model for studying genetic variation in terms of restriction endonucleases. Proc. Natl. Acad. Sci. USA 76: 5269-5273.

Nei M., Tajima F. 1981. DNA polymorphism detectable by restriction endonucleases. Genetics. 97: 145-163.

Nei M. 1987. Molecular evolutionary genetics. Columbia University Press, New York.

Nguyen T.T.T., Ingram B., Sungan S., Gooley G., Sim S.Y., Tinggi D., De Silva S.S. 2006. Mitochondrial DNA diversity of broodstock of two indigenous mahseer species, Tor tambroides and
T. douronensis (Cyprinidae) cultured in Sarawak, Malaysia. Aquaculture 253: 259-269.

Porta J., Álvarez M. 2004. Development and characterization of microsatellites from Senegal sole (Solea senegalensis). Mol. Ecol. Notes 4: 277-279.

Porta J., Porta J.M., Martínez-Rodríguez G., Álvarez M. 2006. Genetic structure and genetic relatedness of a hatchery stock of Senegal sole (Solea senegalensis) inferred by microsatellites. Aquaculture 251: 46-55.

Porta J., Porta J. M., Cañavate P., Martínez-Rodríguez G., Álvarez M. C. 2007. Substantial loss of genetic variation in a single generation of Senegalese sole (Solea senegalensis) culture: implications in the domestication process. J. Fish. Biol. 71: 223-234.

$\mathrm{R}$ Development Core Team 2010. R: A language and environment for statistical computing. R Foundation for Statistical Computing, Vienna, Austria. ISBN 3-900051-07-0, URL http:// www.R-project.org/.

Raymond M., Rousset F. 1995. An exact test for population differentiation. Evolution. 49: 1280-1283.

Reig L., Oca J., Flos R. 2000. Trading perspectives of a potential farmed sole (Solea sp) evaluated at the central fish market of Barcelona (Spain). In: Flos R., Creswell L. (eds.), Responsible Aquaculture in the New Millennium. EAS Special Ppublication 28: 596.

Reig L., Ginovart M., Flos R. 2003. Modification of the feeding behaviour of sole (Solea solea) through the addition of a commercial flavour as an alternative to betaine. Aquat. Living. Resour. 16: 370-379.

Sánchez P., Ambrosio P.P., Reig L., Flos R. 2003. Técnica de biopsia muscular con aguja cortante fina en peces pequeños. In: Consejería de Agricultura y Pesca. Junta de Andalucía. (eds.), Libro de Resúmenes del IX Congreso Nacional de Acuicultura, pp. 360-362.

Sanger F., Nicklen S., Coulson A. R. 1977. DNA sequencing with chain-termination inhibitors. Proc. Natl. Acad. Sci. USA. 74: 5463-5467.

Sekino M., Hara M., Taniguchi N. 2002. Loss of microsatellite and mitochondrial DNA variation in hatchery strains of Japanese flounder Paralichthys olivaceus. Aquaculture. 213: 101-122.

Tinti F., Piccinetti C. 2000. Molecular systematics of the AtlantoMediterranean Solea species. J. Fish. Biol. 56: 604-614.

Tinti F., Piccinetti C., Tommasini S.,Vallisneri M. 2000. Mitochondrial DNA variation, phylogenetic relationships, and evolution of four Mediterranean genera of soles (Soleidae, Pleuronectiformes). Mar. Biotechnol. 2: 274-284.

Van Oosterhout C., Hutchinson W.F., Wills D.P.M., Shipley, P. 2004. MICRO-CHECKER: software for identifying and correcting genotyping errors in microsatellite data. Mol. Ecol. Notes. 4(3): 535-538.

Viñas J., Alvarado Bremer J., Pla C. 2004. Inter-oceanic genetic differentiation among albacore (Thunnus alalunga) populations. Mar. Biol. 145(2): 1-8.

Vu A.T. 1997. Molecular characterization of the Cytochrome b-12S rRNA mitochondrial region in the American alligator (Alligator mississippiensis). Honours thesis, Univ. South Carolina.

Wang J. 2004. Sibship reconstruction from genetic data with typing errors. Genetics. 166: 1963-1979.

Ward R.D., Woodwark M., Skibinski D.O.F. 1994. A comparison of genetic diversity levels in marine fresh-water, and anadromous fishes. J. Fish. Biol. 44: 213-232.

Zorrilla I., Arijo S., Chabrillón M., Díaz P., Martínez-Manzanares E., Balebona M., Moriñigo M. 2003. Vibrio species isolated from diseased farmed sole, Solea senegalensis (Kaup), and evaluation of the potential virulence role of their extracellular products. J. Fish. Dis. 26: 103-108.

Scient. ed.: M. Pascual.

Received June 28, 2010. Accepted January 9, 2012.

Published online May 7, 2012. 